\title{
A agroecologia como estratégia de gestão de Unidades de Conservação de uso sustentável no Vale do Ribeira, Estado de São Paulo, Brasil
}

\author{
GABRIELA NAREZI
}

Universidade Federal do Sul da Bahia

\begin{abstract}
Resumo
Este trabalho apresenta uma reflexão sobre a agroecologia em torno dos diferentes modelos de gestão concebidos para as áreas naturais protegidas. A pesquisa se voltou, em particular, para os debates acerca das Unidades de Conservação de Uso Sustentável do Estado de São Paulo - Brasil. Atualmente, na região do Vale do Ribeira, possuidora de um dos maiores remanescentes contínuos de Mata Atlântica do País, é possível encontrar disputas por diferentes modelos de gestão destas áreas. A metodologia de pesquisa comportou levantamento bibliográfico, anotações em cadernos de campo, entrevistas semiestruturadas e obtenção de relatos orais nos espaços participativos de gestão e uso do território no âmbito da recategorização da Estação Ecológica Jureia-Itatins em mosaicos de Unidades de Conservação. Foi possível encontrar evidências de que o modo de vida e de produção agrícola favorecem uma sensibilidade das populações locais ao início de um processo de transição agroecológica. No entanto, mesmo com a repercussão de experiências agroecológicas de sucesso no Vale do Ribeira, ainda são muito incipientes as iniciativas de conservação da sociobiodiversidade e de valorização cultural no interior de Unidades de Conservação paulistas.
\end{abstract}

Palavras-chave: Agroecossistema. Área Natural Protegida. População Tradicional. Mata Atlântica.

\section{Agroecology as a management strategy for Sustainable Conservation Units in Vale do} Ribeira - SP, Brazil

\section{Abstract}

This paper presents reflections regarding the agroecology in the different management models designed for protected natural areas. Our research is particularly focused in debates about Sustainable Conservation Units in Sao Paulo State in Brazil. Vale do Ribeira is an area that has one of the largest continuous remnants of Atlantic Rainforest of the country. The research methodology included bibliographic analysis and collection of primary data through field notes; oral histories obtained in management and land use participatory spaces at Despraiado RDS in the context of restructuration of Jureia-Itatins Ecological Station in Conservation Units Mosaics; and semi-structured interviews with the 
managers and researchers of Vale do Ribeira Conservation Units. It was possible to find evidence that the way of life and agricultural production of the area favor local sensitivity in regard of an agroecological transition process. However, even with the impact of successful agroecological experiences at Vale do Ribeira, sociobiodiversity conservation initiatives and cultural valorization of sustainable development of traditional populations are still rudimentary at Conservation Units in the State of Sao Paulo.

Keywords: Agroecosystems. Protected Natural Area. Traditional Population. Atlantic Rainforest.

\section{Agroecología y la estrategia de gestión para las áreas protegidas de uso sostenible en el Vale do Ribeira, Estado de São Paulo, Brasil}

\section{Resumen}

Este trabajo presenta una reflexión sobre la agroecologia en torno a los diferentes modelos de gestión concebidos para áreas naturales protegidas. Nuestro interés se ha vuelo, en particular, a las discusiones sobre el uso sostenible de las áreas protegidas del Estado de São Paulo, Brasil. Actualmente, la región del Vale do Ribeira tiene uno de los mayores remanentes continuos de la Mata Atlántica en el país. La metodología de investigación ha consistido en: revisión de literatura; apuntes en cuadernos de campo; entrevistas semiestructuradas; y obtención de informes orales de las reuniones de planificación participativas del Mosaico de Áreas Protegidas JureiaItatins. Es posible encontrar evidencias de que el modo de vida y la producción agrícola favorecen una sensibilidad de las poblaciones locales para el inicio del proceso de transición agroecológica. Sin embargo, existen experiencias agroecológicas de éxito no Vale de la Ribera, más las iniciativas de conservación de la sociobiodiversidad y la recuperación de las culturas tradicionales son todavía muy incipientes en el interior de las áreas naturales protegidas paulistas.

Palabras clave: Agroecossistemas. Áreas Naturales Protegidas. Población Tradicional. Mata Atlántica.

\section{Introdução}

O presente trabalho é oriundo de uma tese de doutorado desenvolvida no Programa de Pós-Graduação Interunidades em Ecologia Aplicada, Escola Superior de Agricultura Luiz de Queiroz e Centro de Energia Nuclear na Agricultura-ESALQ CENA, da Universidade de São Paulo-USP. no âmbito da linha de pesquisa em Ambiente e Sociedade, entre os anos de 2008 a $2012^{1}$.
1 A pesquisa ainda contou com um estágio doutoral no Institute des Hautes Études sur I'Amerique latine (IHEAL), Sorbonne Nouvelle - Paris III, financiado pela Coordenação de Aperfeiçoamento de Pessoal de Nível

Superior (CAPES), no qual foi possível analisar as estratégias de gestão territorial adotadas em dois Parques Naturais Regionais franceses, consideradas enquanto subsídio para nossa análise sobre a conciliação da conservação com o desenvolvimento. 
Os conflitos socioambientais em áreas naturais protegidas trazem inúmeras questões para os debates acadêmicos na área de ambiente e sociedade nos últimos anos. Apesar de ser uma temática bastante aprofundada pelos pesquisadores desta área, a busca por soluções para tais conflitos ainda parece apresentar poucos resultados de sucesso. Assim, o objetivo desta pesquisa foi o de analisar de que maneira a agroecologia é abordada na gestão e uso do território em Reservas de Desenvolvimento Sustentável-RDS do Estado de São Paulo e, neste contexto, identificar os distintos modelos de desenvolvimento e de conservação da biodiversidade que são concebidos para as áreas naturais protegidas no âmbito do Mosaico de Unidades de Conservação Jureia Itatins, na região do Vale do Ribeira, no Estado de São Paulo.

Considerou-se o uso de métodos exploratórios qualitativos, em que diversas técnicas de coleta de dados foram utilizadas. Primeiramente, foram realizados os levantamentos de dados secundários acerca do tema da pesquisa e de caracterização da área de estudo a partir dos dados dos diagnósticos realizados com fins de subsidiar a elaboração do Plano de Manejo do Mosaico de Unidades de Conservação Jureia-Itatins.

Durante todo o processo de aproximação e de envolvimento com o universo da pesquisa, foram realizados registros em campo. Essa técnica de pesquisa para coleta de informações deu-se na forma do diário de campo, coleta de relatos orais (com uso de gravadores) e de registros fotográficos. A obtenção de relatos orais ocorreu nos espaços participativos de gestão e uso do território da RDS do Despraiado, no âmbito da recategorização da Estação Ecológica Jureia-Itatins em mosaicos de Unidades de Conservação-UCs. Em especial, destaca-se a participação nas reuniões do Conselho Gestor Deliberativo da RDS do Despraiado e também nas reuniões de elaboração do Plano de Manejo do Mosaico Jureia - Itatins, entre janeiro de 2008 e setembro de 2009. Como tratavam-se de espaços abertos, foi solicitada, no início de cada reunião, a autorização do uso do gravador e dos registros fotográficos.

Considerou-se o desenvolvimento da observação participante nas reuniões de elaboração do plano de manejo devido à aproximação e a uma maior interlocução junto aos moradores da RDS do Despraiado e demais técnicos e pesquisadores envolvidos. Tais espaços de diálogo foram considerados como essenciais para o estabelecimento de uma relação de confiança entre a pesquisadora e a comunidade envolvida. De acordo com Borges (2009), a observação participante, enquanto método de coleta de dados primários, requer uma relação de convivência com os sujeitos da pesquisa, na qual a observação é feita de maneira direta e a participação busca viabilizar transformações e resoluções de problemas identificados.

Foram realizadas, no total, 20 entrevistas semiestruturadas junto aos diferentes atores sociais envolvidos no contexto da pesquisa. Foram entrevistados oito funcionários da Fundação para a Conservação e a Produção Florestal do Estado de São Paulo. Para a realização destas entrevistas, procurou-se focar nos gestores de UCs na região do Vale do Ribeira de interesse para a pesquisa e nos representantes institucionais do Núcleo de Plano de Manejo, da Assessoria Técnica de Educação Ambiental, do Núcleo de Regularização Fundiária e da Diretoria do Litoral Sul, Vale do Ribeira e Alto Paranapanema. 
Foram realizadas duas entrevistas junto às coordenações das equipes de elaboração do Plano de Manejo do Mosaico de UCs Jureia-Itatins. Foram realizadas seis entrevistas com representantes da população caiçara residente na área de estudo, sendo três lideranças políticas e três moradores (considerados como informantes-chave durante todo o processo de coleta de dados em campo). Além disso, foram entrevistados quatro pesquisadores independentes de diferentes instituições que possuíam vasta experiência em relação à gestão das UCs do Vale do Ribeira. Buscou-se identificar, a partir dos depoimentos desses diferentes atores sociais e institucionais envolvidos no processo de gestão desse território, seus objetivos, suas percepções, perspectivas acerca da conservação da biodiversidade, do desenvolvimento da agricultura bases ecológica no âmbito das UCs de desenvolvimento sustentável, bem como a compreensão dos mesmos acerca dos aspectos multifuncionais da agricultura de bases ecológicas e dos serviços ecossistêmicos associados.

O presente artigo apresenta, a seguir, uma revisão bibliográfica contendo as principais referências conceituais no âmbito da agroecologia, da ecologia humana e ecologia histórica, com destaque para as aproximações entre o manejo ancestral da sociobiodiversidade e as atuais experiências de manejo agroflorestal na Mata Atlântica. Além disso, buscou-se apresentar um breve histórico acerca da concepção de criação das áreas naturais protegidas no Brasil, a implementação do Sistema Nacional de Unidades de Conservação e suas diferentes categorias de gestão, com destaque para as RDSs. Os resultados da pesquisa são apresentados no terceiro item do artigo, buscando apresentar os principais desafios que ocorrem no âmbito da gestão de uma UC de uso sustentável, destacando-se o processo de elaboração do Plano de Manejo da unidade, as disputas paradigmáticas para a conservação da biodiversidade e a emergência do desenvolvimento científico agroecológico capaz de nortear as tomadas de decisão neste contexto.

\section{A agroecologia como estratégia de conservação da biodiversidade}

\subsection{Conceitos e debates acerca da agroecologia}

Os estudos em ambiente e sociedade revelam que a desigualdade social e a alta biodiversidade em ecossistemas tropicais da América Latina geram importantes conflitos socioambientais no que se refere à gestão do território (FERREIRA, 2006), em razão de diferentes visões de mundo e de interesses divergentes quanto ao acesso aos recursos naturais. Por outro lado, é na América Latina e Caribe que se concentram maior aprofundamento e experiências no que se refere à temática da agroecologia. A América Latina destaca-se no que se refere ao surgimento de experiências de desenvolvimento rural e de agriculturas alternativas que se constituem como resistência ao modelo agroindustrial mundial, também contando com espaços de referências históricas e acúmulo de aprendizados acerca das práticas agroecológicas já consolidadas (ALTIERI, 2000).

A antropologia ecológica desenvolve o estudo das relações entre a dinâmica populacional, a organização social e cultural das sociedades humanas e os ambientes nos quais estão inseridas (NEVES, 1996). A aplicação do termo "florestas 
culturais", tal como mobilizado por diversos autores (POSEY, 1985; ADAMS, 1994; CLEMENT, 1999; BALÉE, 2006; DIEGUES, 2004a; ÂNGELO FURLAN, 2006), é utilizado para caracterizar a ocupação dos ecossistemas naturais manejados por populações tradicionais e indígenas, construindo, nesse processo, uma espécie de paisagem domesticada. O manejo tradicional e indígena de um ecossistema florestal pode ser transmitido de geração para geração e pode combinar cultivos agrícolas rotacionados, com coletas de recursos florestais, caça e pesca, tudo proporcionando acesso aos alimentos e a manutenção, e até mesmo o aumento, da biodiversidade local.

Com base em estudos da Antropologia Ecológica, a Agroecologia também considera que "os sistemas agrícolas tradicionais estão baseados, frequentemente, em fundamentos e princípios ecológicos" (ALTIERI, 1989). A pesquisa em agroecologia associa-se, como sugere Sevilla-Guzmán (2002), a estratégias de desenvolvimento rural, tendo na participação social e nas novas formas de ação social e coletivas as bases de produção de conhecimento. Ou seja, a pesquisa ação participativa possibilita o rompimento com estruturas de poder entre pesquisadores e sujeitos de pesquisa e hierarquia de conhecimentos, encontrados na metodologia científica convencional (SEVILLA GUZMÁN, 2002).

De acordo com as interpretações conceituais desenvolvidas no âmbito acadêmico nos últimos anos, a Agroecologia corresponde fundamentalmente a um campo de conhecimento de natureza multidisciplinar que pretende contribuir para a construção de estilos de agricultura de base ecológica e para a elaboração de estratégias de desenvolvimento territorial, tendo-se como referência os ideais da sustentabilidade numa perspectiva multidimensional de longo prazo (CAPORAL e COSTABEBER, 2002).

No contexto das estratégias produtivas agroecológicas, os Sistemas Agroflorestais-SAFs biodiversos vêm ganhando notoriedade, sobretudo por meio de ações coletivas aplicadas à agricultura familiar, a assentados da reforma agrária e a populações tradicionais. Atualmente, já é possível encontrar, no contexto do bioma Mata Atlântica, inúmeras experiências em produção que chamam cada vez mais a atenção. Os SAFs são aqui considerados como "sistemas de uso da terra nos quais espécies perenes lenhosas são intencionalmente utilizadas e manejadas em associações com cultivos agrícolas e/ou animais na mesma unidade de gerência da terra" (MAY e TROVATTO, 2008, p. 29) e apresentam relações ecológicas e econômicas entre estes componentes, constituindo-se como uma alternativa sustentável de ocupação de áreas desmatadas e para cooperar no processo de restauração do patrimônio florestal nativo. A conservação da biodiversidade e a manutenção dos processos evolutivos no âmbito agrícola podem promover a geração de serviços ambientais ou ecossistêmicos (CAMPOS et. al, 2006).

Essas ideias passam a subsidiar o discurso da corrente do movimento socioambientalista que defende outra postura em relação às áreas naturais protegidas. Para conceber as unidades de conservação de uso sustentável, inúmeras ações passaram a ser direcionadas no que se refere à elaboração de políticas públicas de gestão de áreas naturais protegidas, considerando a presença de populações humanas. 


\subsection{O Sistema Brasileiro de Unidades de Conservação}

A implantação do programa "O homem e a biosfera" (MaB), fruto da Conferência sobre a Biosfera, organizada pela Organização das Nações Unidas para a Educação, Ciência e Cultura-UNESCO em Paris, em 1978, e a União Internacional para a Conservação da Natureza e dos Recursos Naturais-UICN incentivaram o Brasil, a partir de 1992, a investir no desenvolvimento de um conjunto de instrumentos legais de controle da exploração dos recursos naturais, notadamente os ecossistemas florestais.

É assim que o Sistema Nacional de Unidades de Conservação-SNUC, criado pela Lei 9.985/2000, fruto de um longo processo de debates e de negociações entre diversos atores sociais, institui, além das UCs de proteção integral (que não permitem a presença humana e o uso dos recursos naturais se restringe a fins científicos e de educação ambiental), aquelas de uso sustentável (que permitem a presença humana, podendo manejar com parcimônia os recursos naturais). Nessa lei, são também instituídos os mosaicos de UCs. Trata-se de um conjunto de UCs de categorias diferenciadas, próximas, justapostas, envolvendo eventualmente outras áreas protegidas públicas ou privadas (BRASIL, 2000).

No caso da implantação de RDS, pode-se considerar que sua conceituação é muito recente, o que explica seu número muito reduzido em relação aos parques e demais unidades de proteção integral em âmbito nacional. O modelo proposto na criação da RDS Mamirauá, em 1996, foi um marco para a história da conservação no Brasil, que inspirou a criação desta categoria posteriormente pelo SNUC. Tratou-se de uma iniciativa pioneira em recategorização da Estação Ecológica Mamirauá, com o objetivo maior de proteger o primata Uacari-branco (Cacajao calvus calvus) e constituída de uma área de reconhecido valor e singularidade ecossistêmica habitada por populações ribeirinhas e caboclas, abrangendo a várzea do Rio Solimões.

Convém explicar que o art. 20 do SNUC conceitua as RDSs como "áreas protegidas que buscam a manutenção das populações tradicionais em áreas de rica biodiversidade cuja utilização sustentável não comprometa a perenidade dos recursos naturais" (BRASIL, 2000). A presença humana deixa de ser um impasse para ser tratada como um elemento potencial de conservação da sociobiodiversidade, partindo do princípio de valorização da cultura ancestral, permitindo gerar renda e dinamizar economias estagnadas a partir da reprodução de modos de vida, no desenvolvimento de atividades produtivas e de manejo de bases ecológicas.

No caso da RDS do Mamirauá, as populações tradicionais desenvolvem o extrativismo, a produção de artesanatos, práticas agrícolas de bases ecológicas e já desenvolvem as primeiras iniciativas em relação ao turismo de bases comunitárias. Destaca-se o modelo de manejo adotado para espécies ameaçadas de extinção, que de um lado são protegidas por lei e, de outro, compõem os modos de vida das populações locais. Os estudos científicos acerca das características biológicas das espécies, suas dinâmicas populacionais, capacidades de regeneração e resiliência, possibilitaram o desenvolvimento de um programa de Manejo de Pesca do Instituto Mamirauá. 
A agroecologia como estratégia de gestão de Unidades de Conservação de uso sustentável no Vale do Ribeira, Estado de São Paulo, Brasil

\subsection{A criação da Estação Ecológica Juréia Itatins: o marco da conservação no Estado de São Paulo}

Efetivamente, o Vale do Ribeira é constituído por remanescentes de Mata Atlântica significativos, formando uma grande reserva do patrimônio natural do estado. Ademais, a região foi declarada Patrimônio Natural da Humanidade, em abril de 1999, pela UNESCO, justamente por ser a maior área preservada de floresta atlântica da região Sudeste do Brasil (MORUZZI MARQUES et.al., 2009).

Esta pesquisa dirigiu-se para o caso da Estação Ecológica Jureia Itatins-EEJI, criada pelo Dec. Estadual 24.646 de 1986. A região comporta uma combinação de ambientes serranos e uma planície - com brejos, lagunas, dunas, a restinga arbórea e arbustiva/herbácea, além de manguezais. "Com quase 80.000 hectares, trata-se de uma das maiores Unidades de Conservação do sudeste do Brasil, o que lhe transformou em símbolo para a preservação da Mata Atlântica." (MARQUES 2004, p.13). Complementando essa paisagem natural, há alguns bairros rurais, de baixa densidade demográfica que mantém ainda sistemas tradicionais de produção concomitantemente às produções agrícolas convencionais degradantes. Tratam-se de populações caiçaras e caboclas que conseguem seu sustento por meio da agricultura, pesca, extração de recursos naturais com baixa capitalização (ISA, 2009).

Inspiradas em experiências amazônicas, associadas à história de luta de Chico Mendes, essa população local passou a se organizar e a lutar pela desafetação do seu território. Sem sucesso em suas reivindicações de desafetação do território tradicional no âmbito da EEJI, no início dos anos 2000, tal movimento orientou-se para uma proposta de recategorização, com vistas à criação de um mosaico de unidades de conservação, no qual fosse possível a delimitação das áreas de RDS, permitindo, assim, a presença humana nos núcleos já existentes.

Em 2006, foi instaurado o mosaico de UCs Jureia Itatins, pela Lei $n^{\circ} 12.406 / 06$ que era composto de sete unidades de conservação: Parque Estadual do Itinguçu, Parque Estadual do Prelado, RDS do Despraiado, Reserva de RDS da Barra do Una e Refúgios Estaduais de Vida Silvestre das ilhas do Guaraú e da Guaritama. O projeto ainda propunha a criação da RDS Una da Aldeia, com 6.789 ha, visando a elevar a área total do mosaico para mais de $117 \mathrm{mil}$ ha. A lei também previa a ampliação da área de 79.230 hectares para 85.270 ha de parte terrestre, que se soma a 6.953 ha de parte marítima. 


\section{Gabriela Narezi}

Figura 1 - Limites do Mosaico de Unidades de Conservação Juréia Itatins, 2006

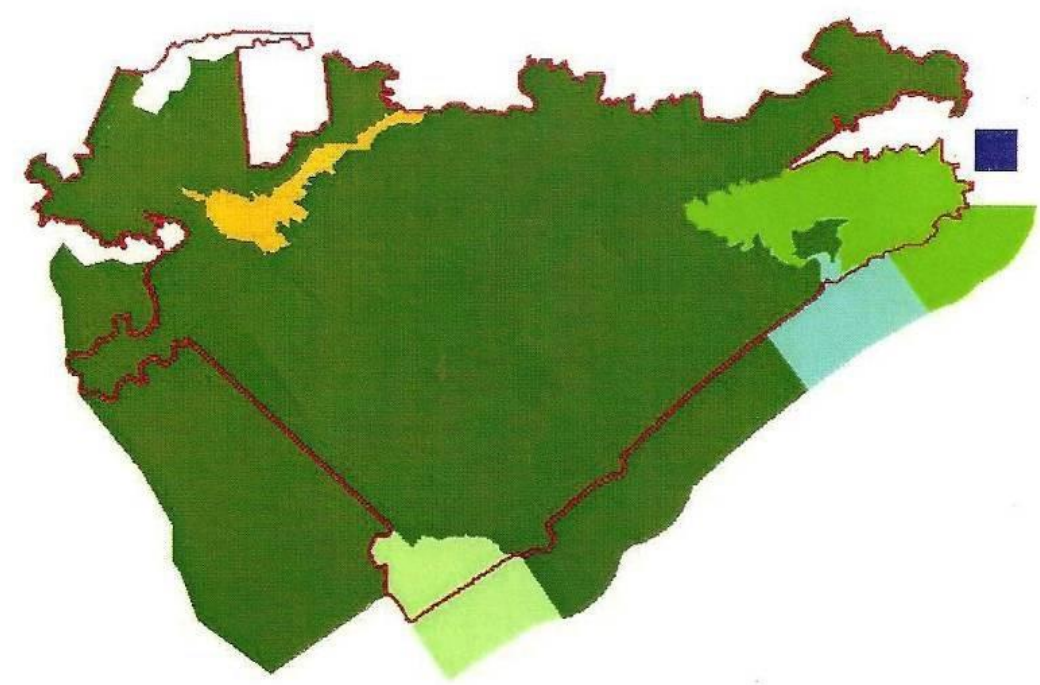

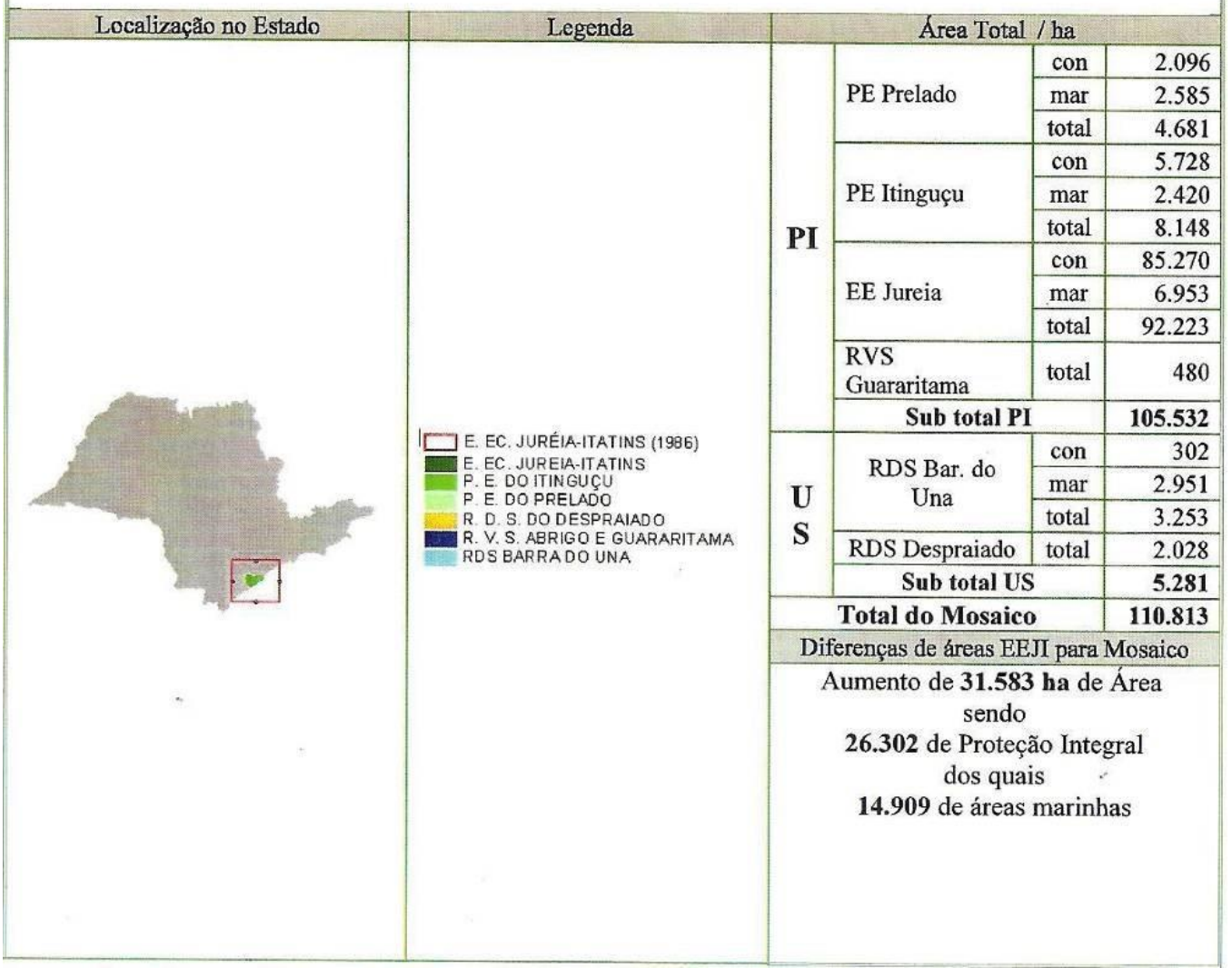

Fonte: SMA, 2010. 
A agroecologia como estratégia de gestão de Unidades de Conservação de uso sustentável no Vale do Ribeira, Estado de São Paulo, Brasil

\section{A emergência da ciência agroecológica na gestão de Unidades de Conservação de uso sustentável}

\subsection{A proposta de criação da Reserva de Desenvolvimento Sustentável do Despraiado}

O núcleo do Despraiado recebeu destaque neste trabalho por tratar-se de uma área que, mesmo possuindo um significativo fragmento florestal, possui expressiva presença da bananicultura e que ainda mantém áreas de moradia, roças para auto-consumo e áreas de criação animal. Uma característica marcante das roças e quintais é o grau de diversidade das plantas, geralmente realizadas em sistemas de policultivos (VIANA, 2004). Os quintais caiçaras possuem uma importância alimentar, medicinal, estética e até mesmo cultural (GARROTE, 2004). No entanto, com a criação da EEJI, houve no núcleo Despraiado a redução efetiva das roças para autoconsumo, predominando as ações extrativistas predatórias e as áreas de monocultivo convencional de banana.

Segundo relatos dos pesquisadores envolvidos no Plano de Manejo do Mosaico de UCs Jureia-Itatins, em visita aos roçados e às capoeiras antigas dos moradores do Despraiado (utilizando um aparelho receptor GPS), observou-se uma alteração no padrão da dimensão dos roçados em comparação a períodos anteriores à criação da EEJI. Os roçados, naquela época, espalhavam-se pelas encostas dos morros e mediam em torno de 1 ou 1,5 ha. Esses roçados foram identificados pelos pesquisadores no ano de 2009 como capoeirões, ou seja, áreas identificadas como aquelas deixadas em pousio há mais de 20 anos pelos moradores.

Os roçados atuais localizam-se mais próximos das residências, são menores e, principalmente, são áreas utilizadas durante os últimos anos, já que é só ali que a gestão da Estação Ecológica autorizou o plantio, inviabilizando o sistema tradicional de rotação de áreas de cultivo e de pousio florestal. Os roçados, até o ano de 2009, encontravam-se em áreas de 0,2 ha, em pequenos aceiros de mata (ISA, 2009).

Além das populações caiçaras que habitam o território da EEJI há mais de 300 anos, no núcleo Despraiado foi possível identificar famílias descendentes de migrantes nordestinos, descendentes de imigrantes japoneses e famílias da região de Iguape, Peruíbe, Santos, dentre outros municípios da região. Estas últimas, em sua maioria, foram atraídas para aquela localidade em busca de empregos na extração do palmito e atualmente são empregados nas atividades da bananicultura.

O núcleo do Despraido, por suas características históricas e geográficas e pelo número de moradores - cerca de 86 famílias (entre residentes e não residentes) distribuídas aproximadamente em 2.028,00 ha - foi uma das parcelas do projeto de Mosaico que sofreu significativos problemas relacionados ao acesso a equipamentos sociais fundamentais à promoção da cidadania. A ocupação humana ocorre basicamente ao longo de um sistema viário desativado que ligava o Município de Pedro de Toledo àquele de Iguape. Em grande medida, a ausência de infraestrutura no local ocorreu em função do seu isolamento geográfico, desenvolvendo atividades estritamente agrícolas, diferentemente dos demais núcleos que se beneficiam do fluxo turístico e atividades pesqueiras por estarem mais próximos do litoral. 
Foi possível identificar que a baixa capitalização na agricultura desenvolvida pelos moradores locais não necessariamente significa ausência de uso de insumos químicos e mecanização nas práticas agrícolas. No caso da bananicultura, são utilizados tais insumos em altas concentrações, pois nota-se que, em diversas áreas, o ecossistema se encontra degradado, fazendo-se necessário o alto implemento de nutrientes externos. Essa situação representa a aplicação precária dos elementos da revolução verde em conjunto com a ausência de assistência técnica para a produção agrícola nessas áreas.

De acordo com o diagnóstico do plano de manejo do Mosaico Jureia-Itatins, o uso da terra atual no Despraiado é predominantemente agrícola e se mantém assim (roças, bananal, pomares, etc) há mais de 20 anos. Em 1989, eram 1.618,00 ha (São Paulo, 1989a) e hoje são 1.390,00 ha sob uso direto e 513,0 ha de uso indireto. Nessas áreas, incluem-se as matas e a vegetação rasteira, consideradas como reservas de coleta de recursos florestais pelas famílias, e os "bananais afogados": antigos bananais abandonados e encobertos pela mata secundária (ISA, 2009, p. 90).

De acordo com os relatos dos moradores locais, as restrições relacionadas à produção agrícola só fizeram aumentar a pressão sobre os recursos florestais, por meio de práticas extrativistas predatórias, notadamente no que se refere à extração da palmeira Juçara (Euterpe edulis), de madeira e de práticas de caça.

A ausência de infraestrutura e acesso aos serviços, conforme apresentados anteriormente, foi elemento promotor da evasão de mulheres e crianças para os centros urbanos da região, em busca de melhores condições de vida, acesso a escolas e demais equipamentos públicos. Tal fato indica a fragilidade da manutenção da cultura local, além da perda do etnoconhecimento e da sociobiodiversidade, visto que as mulheres e os jovens possuem papel essencial na manutenção das roças de autoconsumo e também são considerados fatores-chave para o desenvolvimento de iniciativas agroecológicas.

Os líderes dos moradores do Núcleo Desparaiado se mostraram, inicialmente, desfavoráveis aos projetos alternativos de desenvolvimento e de práticas agroecológicas, pois consideravam que não seria viável adotar medidas diferenciadas de produção numa situação em que não se possuía o mínimo de condições para se viver. Ou seja, esses moradores ainda reivindicavam seus direitos básicos de acesso às condições de vida, como o acesso às tecnologias de comunicação (como telefonia e internet), melhoria das estradas, transporte público, postos de saúde, escolas, entre outros, e eles entendiam que a agroecologia viria como mais uma exigência da gestão da RDS.

Em seu depoimento, um jovem morador do núcleo Despraiado e descendente de moradores tradicionais, disse que trabalhava no corte ilegal do palmito Juçara. Inúmeras vezes esse jovem se manifestou nas reunióes do plano de manejo buscando alertar os técnicos e gestores para a questão do modelo produtivo proposto e da necessidade de uma proposta sólida que garantisse a geração de renda para as famílias (relato coletado em reunião do plano de manejo em agosto de 2009).

Outro morador, mais idoso e também considerado tradicional, já apresentou um ponto de vista menos radical no que se refere ao manejo: "Se nós recebermos incentivos do governo nós podemos fazer outras práticas, mas o problema é que é 
sempre muita exigência e nunca tem apoio pra nada" (relato coletado em reunião do plano de manejo em agosto de 2009).

No que se refere ao processo de adequação da produção agropecuária no interior da RDS, os moradores se mostraram muito incomodados com a extensa lista de restrições. As justificativas dos gestores e técnicos sempre giravam em torno das restrições legais de uso e de ocupação do território, além da grande preocupação acerca da introdução de espécies exóticas no interior das UCs. Tanto no que se refere à produção animal, quanto à produção vegetal, existem sérias restrições legais. Da mesma forma, é o caso do manejo de espécies ameaçadas de extinção, como os frutos da palmeira Juçara. Em entrevista com um gestor da Fundação Florestal, foi possível compreender as barreiras jurídicas que giram em torno da aprovação de um projeto de produção da polpa dos frutos da Juçara, envolvendo a necessidade de elaboração de um estudo de impacto e plano de manejo específico para esta atividade.

A justificativa de manejo das sementes deve ser embasada na intenção de repovoamento da espécie no contexto das UCs de proteção integral. Assim, a despolpa das sementes seria um processo secundário no contexto do objetivo principal que deveria ser a produção de mudas dessa palmeira. Além disso, seria muito oportuno o aprofundamento dos estudos com relação à alimentação da fauna que depende dos frutos da palmeira, além da estruturação de uma rede de comercialização da polpa, garantindo a estrutura de todos os setores que envolvem o processo produtivo.

Assim, o diálogo sobre adequações nos modos de produção agrícola junto aos moradores do Núcleo Despraiado parece exigir não somente uma proposta de inclusão social a partir do reconhecimento e valorização da identidade local e de desenvolvimento territorial com assistência técnica de bases agroecológicas, mas, acima de tudo, sólidas propostas de geração de renda que possam promover a transição das práticas agrícolas para maiores patamares de sustentabilidade ecológica, socioeconômica e cultural.

\subsection{A proposta de zoneamento da Reserva de Desenvolvimento Sustentável do Despraiado}

No que se refere ao processo de elaboração do zoneamento proposto para a RDS no âmbito da elaboração do plano de manejo do Mosaico de UCs Jureia-Itatins, pode-se considerar que o mesmo foi bastante fecundo para os propósitos deste trabalho. A delimitação do território e o zoneamento da área de uma RDS podem expressar os reais usos e ocupação do solo e também podem evidenciar os conflitos em torno desses usos.

O objetivo apresentado pela equipe técnica responsável pela elaboração do plano de manejo foi o de "realizar um zoneamento que considerasse as potencialidades, as vocações, as fragilidades, as suscetibilidades, os acertos, os interesses e os conflitos de seu território" (SMA, 2010). Para tanto, o zoneamento apresentou segmentos da região em porções territoriais, obtidos pela avaliação dos atributos segundo sua relevância e de suas dinâmicas.

Cada setor foi apresentado como uma unidade territorial da paisagem, que passou a ter uma condição de zona quando Ihe é atribuída uma destinação, seja 
para preservação, para pesquisa, para recuperação, para educação, para visitação, para uso sustentável, entre outras (SMA, 2010).

O zoneamento do Mosaico de UCs Jureia-Itatins exigiu das equipes técnicas e demais atores sociais um exercício dialógico que buscasse cruzar os objetivos de cada UC juntamente com as especificações relacionadas ao uso e à ocupação humana, tipos de uso e atividades impactantes decorrentes.

A estratégia desenvolvida pelos técnicos do plano de manejo foi a de elaborar previamente o pré-zoneamento técnico do Mosaico, sendo este o resultado, num primeiro momento, da análise dos diagnósticos do meio físico, biótico e antrópico e do debate técnico e institucional. Essa etapa prévia à reunião pública buscou definir os critérios técnicos que seriam usados na elaboração do zoneamento do Mosaico.

A seguir, são apresentadas as definições de cada zona proposta pela equipe técnica do plano de manejo:

(1) Zona de Uso Extensivo: trilhas que são usadas pelos moradores.

(2) Zona de Recuperação Agroflorestal: Terrenos em escarpa ou de altas declividades, altamente suscetível a escorregamentos e demais processos erosivos. Presença de florestas degradadas, fragmentadas, substituídas pela banana ou com banana sob o dossel (banana afogada), ou alteradas por lavouras e/ou pasto. Vocação de recuperação.

Essa zona foi amplamente discutida pela comunidade e sua definição gerou polêmica entre técnicos e moradores. O principal motivo é que há residências nessas áreas. Assim, a comunidade discutiu que era necessário garantir os usos roças, bananais, moradia, enquanto não houver outra alternativa de renda garantida para esta zona. Foi acordado que os termos de compromisso de uso seriam discutidos no conselho deliberativo e que a recuperação seria gradativa com os acordos garantidos.

(3) Zona de Uso comunitário: Centro de recepção de visitação e educação ambiental, localizada na escola desativada.

(4) Zona de Administração: É um ponto estratégico para orientação de serviços e controle de visitantes.Vocação de gestão.

(5) Zona de Manejo Agroflorestal: Florestas em diferentes estágios sucessionais, em terrenos escarpados ou sem aptidão ou com restrição ambiental. É necessária a sua proteção. Apresenta potencial de manejo de produtos madeireiros e não madeireiros pelos moradores e com boas potencialidades para enriquecimento com espécies de interesse comercial. Vocação de manejo e extrativismo.

Os moradores argumentaram que as melhores áreas para a roça são aquelas de capoeirão e que necessitam abrir roças anuais em sistema rotativo para que garantam a alimentação da família. Os moradores que possuem roças nessa zona exigiram garantias dos técnicos e gestores de que serão autorizados a praticar o sistema de rotação de roças (pousio) por meio de termos de compromissos.

(6) Zona de Uso Agroflorestal: Áreas intensamente alteradas, onde estão concentradas as atuais residências, pomares e rancho. Vocação de uso intensivo. Essa área é onde se concentra a maior parte dos usos do Núcleo do Despraiado.

A partir da apresentação das descrições e das características de cada zona, os técnicos e a população local discutiram o que "pode e o que não pode" ser feito 
em cada uma delas, baseando-se em dados coletados a partir dos diagnósticos do meio biótico, físico, antrópico, associados às análises de capacidade de carga, regulamentações específicas para o zoneamento em UCs de uso sustentável e para estratégias de manejo de recursos naturais previamente validadas. O método adotado, mesmo que elucidativo, pareceu conflituoso. Ficou evidente para a população que poucas propostas estavam sendo feitas em termos de geração de renda e garantia da possibilidade de produção agropecuária.

A princípio, a perspectiva de gestão participativa de uma RDS implica que as propostas geradas a partir da oficina de programas pela população sejam elementos-chave para a escolha das áreas prioritárias para o manejo e também para a conservação, além de zonas e subzonas. Essas escolhas podem ser cruzadas com os levantamentos científicos com prioridades estabelecidas, resultando num zoneamento mais consensuado e participativo. No entanto, os moradores manifestavam desacordo com o excesso de restrições estabelecidas.

Segundo relatos dos moradores, após a finalização das oficinas de zoneamento do plano de manejo, ainda restaram muitas dúvidas acerca das terminologias adotadas para as zonas da RDS (zona de uso extensivo, intensivo, uso agroflorestal, recuperação agroflorestal etc, conforme descrito anteriormente). Tais terminologias não fazem parte do vocabulário cotidiano das famílias e tampouco possibilitam uma única interpretação.

\subsection{A gestão da Reserva de Desenvolvimento Sustentável do Despraiado e a demanda do manejo agroecológico}

No decorrer das reuniões do plano de manejo, algumas famílias já apresentavam seus produtos, denominando-os agroecológicos e frutos de suas tradições culturais - geleia de Cambuci (Campomanesia phaea), geleia de Jambo (Syzygium jambos L.), produção de farinha d'água de Mandioca (Manihot esculenta), artesanatos em Caixeta (Tabebuia cassinoides), hortaliças, óleos, tinturas e essências enquanto produtos de usos medicinais. Uma das moradoras entrevistadas apresentou-se como sendo uma das poucas adeptas de prática agroecológica no interior do núcleo do Despraiado. Em busca de formação e melhoria de sua produção, ela entrou em contato com instituições da região do Vale do Ribeira, tais como o Programa da Terra-PROTER e, a partir disso, foi possível participar de cursos de formação e inseriu-se em feiras livres da região.

Segundo relatos de um funcionário da Fundação Florestal, ex-gestor do Núcleo do Despraiado, no momento inicial de sua gestão, foram realizadas visitas de intercâmbio em áreas de experiências produtivas em sistema agroflorestal. Uma das visitas foi realizada na região da Barra do Turvo, na sede da Cooperafloresta, considerada uma grande referência na produção em Sistema Agroflorestal biodiverso na região do Vale do Ribeira.

Os moradores participaram de uma oficina sobre os conceitos básicos de um sistema agroflorestal e também realizaram uma experiência prática de manejo. Entretanto, alguns moradores consideraram que não houve uma identificação com o sistema de produção visitado. Por outro lado, o fato da distância e as dificuldades de acesso podem ter influenciado, segundo os relatos do então gestor. $\mathrm{Na}$ sua interpretação, essa vivência pareceu pouco agradável aos participantes, pois 
efetuaram atividades pouco habituais. Ademais, o sistema de produção visitado pouco representa as práticas que esses moradores estão acostumados a desenvolver em suas rotinas e em suas roças.

Essa experiência revela as dificuldades de sensibilização e envolvimento de determinadas populações com características culturais e hábitos específicos para a prática agroecológica. Cabe ressaltar que, notadamente no caso das UCs de uso sustentável, o papel do gestor não está somente relacionado ao processo burocrático e administrativo de gestão e proteção da área em si, mas, sobretudo, ao exercício diário do contato, da aproximação, do envolvimento e da conquista da confiança dos diferentes atores sociais que compõem o cenário da gestão. De acordo com relatos obtidos nas entrevistas, na grande parte das situações é o gestor da UC que assume as responsabilidades administrativas e também de orientação técnica, na execução de ações relacionadas ao manejo, no desenvolvimento de projetos, de estabelecimento e articulação das normas de convivência junto às populações envolvidas etc.

Os funcionários da Fundação Florestal que foram entrevistados relataram que os gestores são graduados na área de ciências naturais (predominantemente nos cursos de Biologia, Geografia e Engenharia Florestal) e todos declararam que não sentiam-se totalmente aptos para atuarem em projetos e não sentiam-se familiarizados com a temática da agroecologia ou com questões acerca dos conflitos socioambientais.

Para desempenhar com êxito um volume de responsabilidades, a definição de uma carreira profissional parece essencial, associada ao treinamento relacionado às legislações pertinentes e aos mecanismos de fiscalização (já previsto em cursos oferecidos pelo Instituto Chico Mendes de Preservação da Biodiversidade-ICMBio, além de uma formação continuada do gestor em temas relacionados às práticas participativas, educação ambiental, agroecologia e demais conteúdos que auxiliem a gestão em sua rotina. Entende-se que tais embasamentos podem possibilitar não somente a qualidade da relação entre UC e população, mas também propiciar ações mais eficazes de proteção do patrimônio natural por meio da aproximação dos agentes sociais envolvidos para o campo da gestão participativa do território.

Segundo relatos de um morador tradicional do núcleo do Despraiado, algumas pequenas mudanças na gestão ocorreram após a criação da RDS, como a vinda de uma escola na área da comunidade. Entretanto, o morador destaca que muitas promessas deixaram de ser cumpridas por parte do órgão gestor. Os gestores alegavam que só seria possível dar início aos projetos e viabilizar as demandas da população quando o plano de manejo fosse concluído e aprovado. Durante esse período os moradores foram submetidos a restrições semelhantes àquelas da Estação Ecológica.

Em entrevista com gestores, foi possível identificar a fragilidade desse cargo perante à aplicação das leis e ao relacionamento conflituoso com a população. $O$ cargo de gestor é, por vezes, de confiança do governo do estado ou, em outros casos, indicado a um funcionário concursado. Em ambas as situações, nota-se que não há nenhuma vantagem em termos de definição de carreira, supostamente não tendo direitos e deveres bem definidos, reduzindo ainda mais suas possibilidades de atuação. 
Portanto, a definição da carreira do gestor de unidade de conservação pode ser considerada como essencial para o bom andamento dos processos junto à comunidade, principalmente no que se refere à solução de conflitos socioambientais. Além disso, observou-se que a estrutura montada para a elaboração do plano de manejo de uma UC é centralizada no papel do pesquisador, dos técnicos e consultores contratados. Nesse processo, há um significativo afastamento do gestor da UC e da população local, sendo secundários nos processos de tomada de decisão, apesar dos esforços em se garantir uma participação mínima dos atores sociais envolvidos.

No entanto, após a elaboração do plano de manejo, é o gestor e a população local que deverão interagir, embasados nas diretrizes estipuladas. Nesse momento, não há mais uma equipe de pesquisadores, técnicos e consultores e nem sempre a estrutura para a execução do plano é a mesma daquela de sua elaboração. Assim, essa descontinuidade implica em que, por vezes, o plano de manejo não passe de um instrumento burocrático.

Um ponto polêmico que surgiu no contexto do zoneamento foi a questão da presença da pecuária na área da RDS. A regulamentação apresentada pelos técnicos do plano de manejo limitava em três cabeças de gado por família, o que não foi aceito pelos moradores. Havia famílias no núcleo Despraiado que desenvolviam a atividade da pecuária leiteira e de corte e possuíam esta atividade como principal fonte de renda, sendo uma grande preocupação tal limitação.

Cabe destacar aqui que a lógica utilizada pelos técnicos e gestores para o estabelecimento de três cabeças de gado por família baseia-se na noção de autoconsumo a partir de um cálculo de capacidade suporte em uma possível área de pasto coletivo num sistema de manejo convencional, desconsiderando alguma possibilidade de produção de interesse comercial ou com perspectiva de geração de renda. Ao serem interpelados sobre esta questão, os gestores entrevistados declararam desconhecer uma alternativa de bases ecológicas e sustentáveis para a pecuária e até mesmo desconhecem as estratégias produtivas agroecológicas.

Já os moradores revelaram uma receptividade em conhecer essas possíveis alternativas para a pecuária ecológica. Pode-se considerar que foi a partir dessa discussão que houve uma maior compreensão acerca da importância da agroecologia em relação aos ajustes em suas práticas produtivas. Foi possível notar que há uma grande demanda por acesso à informação no que se refere a novas estratégias e técnicas de manejo agroecológico, tanto por parte dos moradores quanto por parte dos gestores, técnicos e pesquisadores responsáveis pela elaboração do plano de manejo de uma UC. Pode-se considerar que os moradores, inicialmente, apresentaram certo estranhamento à temática proposta por esta pesquisa. No entanto, no decorrer das atividades do plano de manejo, foi estabelecido um contato e uma relação de diálogo que foi capaz de traduzir aos moradores do núcleo do Despraiado, ainda que de maneira secundária, do que tratam as práticas da agroecologia. 


\subsection{As propostas de infraestrutura e as estratégias de geração de renda na Reserva de Desenvolvimento Sustentável do Despraiado}

Após o conturbado processo de definição do zoneamento das unidades do Mosaico Jureia-Intatins, iniciou-se o processo de elaboração dos programas de gestão deste território. As primeiras demandas apresentadas pelos moradores estavam relacionadas à qualidade de vida. Essas demandas envolviam questões ligadas ao acesso a serviços, à educação e também à infraestrutura local. Só depois começaram a surgir as propostas relacionadas ao manejo, às práticas agrícolas e à gestão. Alguns consultores do plano de manejo alegaram que, a partir do acesso à infraestrutura, os moradores passariam a acessar bens de consumo que poderiam ser incompatíveis com os objetivos de conservação da unidade. Esse posicionamento foi foco de muita polêmica, visto que os moradores responderam dizendo que: "quem faz esta crítica, nunca viveu restrições em seu bem-estar, pois sempre morou na cidade" (relato coletado em reunião do plano de manejo em setembro de 2009).

A demanda por uma estrutura de saneamento ambiental, envolvendo coleta seletiva de resíduos sólidos, desenvolvimento de técnicas de compostagem de resíduos orgânicos e tratamento dos esgotos domésticos foram acordadas entre técnicos, pesquisadores e moradores. Essa demanda também envolve a ampliação da visitação turística e as estruturas do órgão gestor no interior da RDS. A perenização das estradas é um item de extrema importância para os moradores locais, por viabilizar o transporte público, o escoamento da produção agrícola e demais produtos, além de viabilizar o acesso aos centros de saúde e escolas dos bairros circunvizinhos.

No que se refere às demandas relacionadas ao manejo, destacou-se a necessidade apresentada pelos moradores e pelos gestores das UCs de desenvolvimento de processos formação em manejo sustentável dos recursos naturais locais. Houve, uma declaração acerca da importância de desenvolvimento de cursos em agroecologia, sendo este momento de grande importância para esta análise. Além disso, a importância da diversificação nas fontes de geração de renda foi destacada como essencial para a sustentabilidade das famílias do interior do núcleo do Despraiado. Por encontrarem-se numa área mais isolada, o desenvolvimento das atividades de turismo seria secundário, ligadas mais fortemente a grupos de pesquisadores, escaladores e grupos de estudantes. Em contrapartida, a produção agrícola com foco no abastecimento turístico dos municípios da região mostrou-se como potencial mais fecundo. Além disso, os moradores manifestaram interesse na produção e manejo de recursos florestais para o atendimento de indústrias de fármacos, cosméticos e de inserção a projetos ligados à programas de pagamento por serviços ambientais.

Pode-se considerar que a ocorrência de uma significativa demanda em relação ao acesso ao conhecimento de práticas agroecológicas, notadamente no caso dos sistemas agroflorestais, deve ser encarado como um grande potencial de reconhecimento da multifuncionalidade da propriedade agroecológica. Ou seja, o desenvolvimento de experiências agroecológicas de sucesso no Vale do Ribeira passa a ser referência em sistematização e formação do conhecimento agroecológico. 
Dessa forma, foi possível identificar nas iniciativas agroecológicas do Vale do Ribeira certa correlação entre os programas de agro e ecoturismo, de produção em sistemas agroflorestais, de espaços de formação em agroecologia e comercialização direta de produtos. O desenvolvimento de novas estratégias de dinamização territorial atraem aqueles indivíduos interessados em conhecer novas referências de produção e de desenhos de agroecossistemas em diferentes níveis de sustentabilidade.

Esse conjunto de experiências - em produção a partir de sistemas agroflorestais, em agroecoturismo e em espaços de formação em agroecologia permite considerar que, em grande medida, a agroecologia associada ao agroecoturismo cria oportunidades inéditas para um reconhecimento de diferentes papéis da agricultura familiar, notadamente recolocando a mulher no centro das atividades desenvolvidas. A gastronomia, a diversificação agroflorestal, a complexificação da paisagem a partir da unidade produtiva pertencem a uma esfera de atividades na qual o papel da mulher reencontra seu espaço de atuação no universo rural.

Em nossas entrevistas e visitas de campo, foi possível constatar que o manejo agroflorestal se mostra adequado às características pedológicas, climáticas e socioculturais da região do Vale do Ribeira. Além da possibilidade de regulamentação do manejo da palmeira Juçara, segundo Clóvis J.F. Oliveira Júnior (2010), pesquisador do Instituto de Botânica de São Paulo, no território da EEJI e seu entorno, há um grande potencial de aproveitamento econômico a médio e longo prazo de espécies de bromélias, orquídeas e samambaias, que podem ser inseridas em cadeias produtivas sustentáveis, regulamentadas por leis ambientais e de proteção. A produção de "plantas nativas são capazes de ocupar espaço crescente no mercado da floricultura e paisagismo, por seus requisitos diferenciais" (OLIVEIRA JÚNIOR, 2010, p. 1068). Além disso, também destacam-se os potenciais de produção de plantas aromáticas e medicinais para a produção de óleos essenciais de interesse para a indústria de fármacos e de cosméticos, setor em destaque de crescimento no Brasil nos últimos anos.

Nesse sentido, os processos de adequação da produção agrícola e do manejo sustentável podem ser orientados para a obtenção de certificação ambiental e florestal, já aplicados aos casos de manejo sustentável em comunidades amazônicas. Entende-se que a certificação pode transformar os processos de exploração predatória e pode estimular ações em prol do manejo de bases ecológicas, atingindo mercados diferenciados e agregando valor aos produtos da biodiversidade. A geração de renda diversificada tem como seu objetivo maior a valorização da sociobiodiversidade local e a redução da pressão ocasionada pela prática extrativista ilegal predatória.

Ressalta-se que a demanda por formação em sistema de manejos sustentáveis e em agroecologia foi unânime entre os moradores do núcleo do Despraiado, que consideraram necessária a criação de um curso técnico para os jovens da comunidade. No entanto, de acordo com os relatos dos moradores, as cobranças do órgão gestor com relação às normas de permanência das famílias no interior de uma RDS são muitas, mas poucas são suas contrapartidas. 


\subsection{Disputas paradigmáticas para a conservação da biodiversidade no âmbito do Mosaico de Unidades de Conservação Jureia-Itatins}

Apesar dos inúmeros esforços mobilizados em torno da elaboração do Plano de Manejo, a lei de criação do Mosaico de UCs Juréia Itatins foi revogada em 2009 por uma Ação Direta de Inconstitucionalidade-ADIn movida pelo Ministério Público Estadual, revelando, em grande medida, a força de uma concepção preservacionista neste processo. Entre as fundamentações para essa ADIn, estava o "vício de origem", tendo em vista que a lei foi proposta por iniciativa do legislativo paulista, quando deveria ter sido do Poder Executivo. Além disso, alguns pesquisadores e representantes do governo argumentavam que os estudos e as avaliações de impacto ambiental para a criação do mosaico eram insuficientes. Como consequência, ocorreu a paralisação dos trabalhos de elaboração dos Planos de Manejo e novas ações de retirada dos moradores ocorreram.

De toda maneira, o debate em torno da perspectiva de sua implantação revela as diferentes concepções de desenvolvimento em jogo no Vale do Ribeira. Em boa medida, a história de marginalização das populações afetadas favorece a manutenção de sua invisibilidade política, desfavorecendo as estratégias desenvolvimento territorial sustentável.

De acordo com os relatos de funcionários da Fundação Florestal e de pesquisadores entrevistados, existem significativos impedimentos burocráticos e resistências ideológicas referentes à proposta da produção agroecológica em áreas naturais protegidas, sobretudo em razão da possibilidade de introdução de espécies exóticas em áreas destinadas à conservação da biodiversidade. Tal problema pressiona o campo das pesquisas em agroecologia no sentido de priorizar o desenvolvimento de investigação acerca da funcionalidade agroecológica das espécies nativas, além do desenvolvimento de planos de uso destas espécies que possibilitem o seu aproveitamento econômico e a manutenção de suas funções ecossistêmicas de maneira equilibrada.

Efetivamente o estudo focado em uma RDS do mosaico de UCS Jureia-Itatins foi desafiador e instigante. As posições de seus atores, com suas lutas e contradições, refletem uma situação complexa. Os conflitos socioambientais nessa área natural protegida revelam os impasses em torno da concepção das RDSs. No Estado de São Paulo, as demandas em favor da consideração mais adequada dos modos de vida e da reprodução social de populações tradicionais são insuficientemente canalizadas e recebidas nas instâncias de tomada de decisão na política ambiental. Essas demandas por outras estratégias de gestão para essas áreas aspiram à minimização dos conflitos, valorizando mecanismos de manejo sustentável dos recursos naturais disponíveis na Mata Atlântica.

Conforme apresentado na revisão bibliográfica deste trabalho, o histórico de criação das áreas naturais protegidas apresenta os diferentes paradigmas que envolvem os processos de tomada de decisão na gestão de territórios naturais. No caso da EEJl, esses paradigmas impregnam efetivamente as concepções que orientam os atores implicados. A partir do trabalho de campo, foi possível identificar diferentes discursos acerca dos modelos de conservação da sociobiodiversidade e da biodiversidade, fundados em paradigmas distintos. 
O histórico das políticas públicas ambientais e da formação do movimento ambientalista, notadamente no Estado de São Paulo, revela a ancoragem da criação de áreas naturais protegidas no modelo preservacionista. Além disso, este histórico também apresenta significativos embates dessa perspectiva frente ao discurso socioambientalista, que defende os direitos de permanência de populações tradicionais em áreas naturais protegidas.

As evidências identificadas nos discursos de técnicos, pesquisadores, gestores e interlocutores da população local permitem analisar as controvérsias no âmbito da conservação da biodiversidade e da prática agroecológica, enquanto ferramenta de gestão de unidades de conservação.

O discurso preservacionista paulista foi embasado por inúmeras referências teóricas, entre elas destacam-se as formulações de Warren Dean: "Tão pouco resta que nada pode ser destinado a experimentos de "desenvolvimento sustentado"; de fato, todas as propostas do tipo com relação à Mata Atlântica devem ser vistas como insinceras e hipócritas" (DEAN, 1996, apud OLMOS E GALETTI, 2004, p. 360).

Ainda Olmos e Galetti (2004) apresentam que, apesar das controvérsias acerca dos modelos de gestão, a criação das UCs ainda é a melhor estratégia para a proteção da biodiversidade. No entanto, os autores ressaltam que a presença humana nessas áreas naturais protegidas representam grandes ameaças à efetividade da preservação.

Mesmo que caçadores e moto-serras não sejam mais um problema, existem ameaças da invasão por espécies ruderais (em geral exóticas), mudanças climáticas induzidas por padrões regionais de uso da terra, poluição, pesticidas, desequilíbrios biológicos e incêndios provenientes de áreas circunvizinhas (OLMOS \& GALETTI, 2004).

Em geral, nota-se que a introdução de espécies exóticas é indicada como primeiro problema da presença humana em áreas naturais protegidas. Nesse sentido, os autores mencionados acima criticam propostas de presença humana em áreas naturais protegidas, com o argumento contrário à introdução de espécies exóticas. Paradoxalmente, autores ligados aos movimentos socioambientalistas interpretam tal fenômeno como "aumento de biodiversidade", discurso efetivamente atrelado aos sistemas agroflorestais, conforme destacado na revisão bibliográfica deste trabalho.

Para os primeiros autores, com a presença humana, a UC pode até ganhar em diversidade de habitat, mas pode perder em qualidade (exóticas $\mathrm{x}$ nativas) ou em diversidade real. Além das espécies vegetais, tais como gramíneas africanas, bananeiras, leguminosas etc. Os autores em questão também citam a presença de animais domésticos, tais como cachorros, gatos, marrecos, patos, peixes, cavalos, porcos e gado, animais que, por vezes, possuem acesso livre à floresta (OLMOS \& GALETTI, 2004).

Outra contestação apresentada pela linha preservacionista se refere à suposta sustentabilidade das práticas agrícolas tradicionais. A roça caiçara apresenta a prática do corte e queima - a coivara, que é considerada por alguns autores (GARROTE, 2004) como uma prática sustentável, pois garante o aporte de nutrientes ao solo, favorecendo-lhe a fertilidade. No entanto, a coivara pode também favorecer a perda de espécies chave para o alcance de maior complexidade do sistema. Além disso, a prática do pousio e da rotação de culturas, cujo ciclo dura 
no máximo 12 anos (ADAMS, 2006), não é considerada sustentável para outros autores, pois não favorece a formação de estágios avançados.

Considerando-se que as áreas destinadas à agricultura na EEJI correspondem a aproximadamente $4 \%$ de sua área total (SANCHEZ, 1997) e que a localização desta área cultivada ou cultivável se dá nos ambientes de planície litorânea e encostas, pesquisas citadas por Olmos e Galtetti são capazes de concluir que a agricultura caiçara compete diretamente por espaço com as espécies restritas aos ecossistemas de restinga e de encostas (OLMOS \& GALETTI, 2004).

Além dos argumentos apresentados anteriormente, a crítica ao socioambientalismo formulada pela corrente preservacionista, no contexto da Mata Atlântica, também norteia-se pelo questionamento da sustentabilidade, supostamente promovida pela cultura caiçara. Ou seja, assim como houve a difusão da crítica ao modelo preservacionista por meio do mito moderno da natureza intocada (DIEGUES, 2004), por outro lado, há também a difusão do mito do "bom selvagem" por determinados pesquisadores ligados à linha socioambientalista. Desse modo, Cristina Adams identificou a falta de uma "abordagem ecológica séria e de uma base empírica confiável na literatura, o que muitas vezes tem levado a considerações na linha do discurso ecológico romântico, que tendem a vincular a imagem dos caiçaras ao mito do bom selvagem" (ADAMS, 2000, p. 145), aquele que em todas as situações contribui com o aumento e conservação da biodiversidade.

Os diversos ciclos econômicos pelos quais passou a cultura caiçara do litoral paulista foram significativos no que se refere às alterações nos processos culturais e à inserção de hábitos comerciais, de consumo e de relação com o meio (ADAMS, 2000). Nesse sentido, considera-se a necessidade de aprofundamento dos estudos interdisciplinares acerca dos hábitos e modos de vida de populações que habitam UCs e demais áreas naturais de interesse para a conservação, para além daqueles que foram propostos pelo Plano de Manejo do Mosaico de UCs Jureia-Itatins. Além disso, o envolvimento e a participação das populações tradicionais nos diagnósticos, levantamentos e estudos se mostram como fatores essenciais para a qualificação destes trabalhos.

Destaca-se que em abril de 2013, o Mosaico foi restabelecido pela lei $\mathrm{n}^{\circ}$ 14.982 , sendo a ADIN considerada improcedente. Foi retomado o processo de finalização do plano de manejo e foram previstos recursos para desenvolvimento de projetos de uso sustentável, recuperação de áreas degradadas, saneamento básico, comunicação, entre outros.

\section{Considerações finais}

A proposta desta pesquisa consistiu em apresentar elementos e reflexões sobre a dicotomia da relação entre homem-natureza e sobre os distintos modelos de desenvolvimento que são concebidos para as áreas naturais protegidas, em especial as UCs de uso sustentável. Atualmente, na região do Vale do Ribeira é possível encontrar disputas por diferentes modelos de gestão destas áreas, em especial no que se refere à categoria das RDS do Estado de São Paulo - Brasil. Buscou-se analisar as mais recentes formas de reconhecimento do direito de permanência de populações tradicionais no interior de áreas naturais protegidas no Brasil, em especial, na faixa de Mata Atlântica do litoral sul paulista. 
Além disso, buscou-se analisar a inserção da temática da agroecologia como ferramenta de gestão e de solução de conflitos em razão da presença humana nessas áreas. Considera-se que as RDSs apresentam novas possibilidades de contratos territoriais entre sociedade civil (representada pela população local) e o Estado (em termos de políticas públicas ambientais representadas pelas instituições públicas gestoras). Elas são caracterizadas por novas propostas de reprodução social de populações tradicionais até então marginalizadas, bem como o reconhecimento de dinâmicas e de manejos dos agroecossistemas, buscando formas sustentáveis na relação homem-natureza.

O debate em torno da perspectiva de implantação do Mosaico de UCs JureiaItatins revelou as diferentes concepções de desenvolvimento em jogo no Vale do Ribeira. Efetivamente, a partir dos objetivos da pesquisa, foi possível lançar luzes sobre diferentes referenciais de sustentabilidade em torno do debate sobre a conservação e sobre o desenvolvimento para a região. No caso da Estação Ecológica Jureia-Itatins - em especial no que se refere à proposta de recategorização para o modelo de mosaico de UCs, considerando a implantação de RDSs - é marcada pela forte luta das populações tradicionais e demais moradores locais, imprimindo traços que evoluem para além do reconhecimento dos direitos de permanência.

Trata-se dos arranjos de uma mudança paradigmática nos referenciais de desenvolvimento e de conservação da biodiversidade para essa região. Se repetidas vezes, no decorrer do histórico do Vale do Ribeira, as populações tradicionais foram consideradas como um entrave ao desenvolvimento, o debate socioambientalista e a perspectiva agroecológica, são em certa medida, mobilizadas para favorecer um reconhecimento da cultura e modos de vida destas populações. Quanto às hipóteses da pesquisa, considera-se que o lugar do debate agroecológico no âmbito da gestão de uma RDS é, de fato, incipiente. Porém, cresce a defesa, ao menos no âmbito dos discursos, de uma transição do modelo produtivo atual, buscando a recuperação de áreas degradadas ou a preservação da matas remanescentes com a adequação dos modos de vida das famílias.

Finalmente, esse cenário nos possibilita considerar que está em aberto o convite para a construção de um novo percurso para a gestão de UCs de uso sustentável em termos de aprofundamento sobre os processos de participação social, além de novos e contínuos estudos sobre o papel das estratégias de produção agrícola de bases ecológicas na promoção da conservação da biodiversidade.

\section{REFERENCIAS}

ADAMS, C. As florestas virgens manejadas. Bol. Mus. Para Emilio Goeldi. Série Antropologia, v. 10, n. 1, p. 3-20, 1994.

ADAMS, C. Caiçaras na Mata Atlântica: pesquisa científica versus planejamento e gestão ambiental. São Paulo: Annablume, FAPESP, 2000. 
ALTIERI, M. Agroecologia: as bases científicas da agricultura alternativa. Rio de Janeiro: Edição AS-PTA Assessoria e Serviços a Projetos em Agricultura Alternativa,1989.

ALTIERI, M. Agroecologia: a dinâmica produtiva da agricultura sustentável. Porto Alegre: 2ed. Ed. UFRGS, 2000.

ÂNGELO FURLAN, S. Florestas Culturais: manejo sociocultural, territorialidades e sustentabilidade. Agrária, n.3, p. 3-13, 2006.

BALÉE, W. The research program of historical ecology. Annual Review of Anthropology, v.35, p. 75-98, 2006.

BORGES, M.C. Da observação participante à participação observante: uma experiência de pesquisa qualitativa. In: RAMIRES, J.C.L., PESSÔA, V.L.S. (Orgs.). Geografia e pesquisa qualitativa nas trilhas da investigação. Uberlândia: Assis, p.183-198, 2009.

BRASIL. Sistema Nacional de Unidades de Conservação da Natureza - SNUC. Lei n. 9.985, de 18 de julho de 2000. Brasília: IBAMA/DIREC, 2000.90

CAMPOS, J.B.; TOSSULINO, M.G.P.; MULLER, C.R.C. Unidades de Conservação: ações para a valorização da biodiversidade. Curitiba: Instituto Ambiental do Paraná, 2006.

CAPORAL, F.; COSTABEBER, J. Agroecologia: enfoque científico e estratégico. In: Agroecologia e Desenvolvimento Rural Sustentável. Porto Alegre, v.3, n.2, abr/jun, p 13-16, 2002.

CLEMENT, C.R. 1492 and the Loss of Amazonian Crop Genetic Resources Crop Biogeography at Contact. In: Economic Botany, v.53, n.2, p. 203-216, Apr/Jun, 1999.

DIEGUES, A.C. O mito moderno da natureza intocada. São Paulo: Hucitec, Nupaub USP, 2004.

FERREIRA, L.C. Dimensões humanas da biodiversidade: mudanças sociais e conflitos em torno de áreas protegidas no Vale do Ribeira, SP, Brasil. Ambiente e Sociedade, v. 7, n.1, p. 47-66, jan/jun, 2004.

FREIRE, P. Pedagogia do oprimido. Rio de Janeiro: Paz e Terra, 1975.

GARROTE, V. Os quintais caiçaras, suas características sócio-ambientais e perspectivas para a comunidade do saco do Mamanguá. Paraty - RJ, 2004.

INSTITUTO SOCIOAMBIENTAL - ISA. Análise Sócio-Cultural e Econômica nas RDS. Relatório Final para elaboração do Plano de Manejo do Mosaico de Unidades de Conservação de Juréia-Itatins. Peruíbe, 2009. 
A agroecologia como estratégia de gestão de Unidades de Conservação de uso sustentável no Vale do Ribeira, Estado de São Paulo, Brasil

MARQUES, O.A.V. Estação Ecológica Juréia-Itatins: Ambiente físico, flora e fauna. Ribeirão Preto: Holos Editora, 2004.

MAY, P.; TROVATTO, C. Manual Agroflorestal para a Mata Atlântica. Brasília: Ministério do Desenvolvimento Agrário, 2008.

MORUZZI MARQUES, P. E.; NAREZI, G.; HADDAD, C.; CHAHIN, C. B. Agricultura de sustentação quilombola e desenvolvimento: estudo de projetos em concorrência. In: CONGRESSO BRASILEIRO DE SOCIOLOGIA: CONSENSOS E CONTROVÉRSIAS. SBS. Anais..., CD-ROM. Rio de Janeiro, 2009.

NEVES, W. Antropologia ecológica: um olhar materialista sobre as sociedades humanas. São Paulo: Cortez, v. 59, 1996.

OLIVEIRA JÚNIOR, C.J.F.; NEVES, Y.T.R.; JUNQUEIRA, P.S. População caiçara, Mata Atlântica e situação atual do palmito-juçara (Euterpe edulis Mart.) na região do rio Uma da Aldeia (Iguape - SP), entorno da Estação Ecológica Juréia- Itatins. Revista Árvore, Viçosa-MG, v.34, n.6, p.1065-1073, 2010.

POSEY, D. A. Indigenous management of tropical forest ecosystems: the case of the Kayapó Indians of the Brazilian Amazon. Agroforestry Systems, v.3, n.2 : 139-158. Holualoa - Hawai, 1985.

SECRETARIA DO MEIO AMBIENTE DO ESTADO DE SÃO PAULO - SMA. Estudo técnico para recategorização de unidades de conservação e criação do mosaico de unidades de conservação Juréia-Itatins. São Paulo: Fundação Florestal, 2010.

VIANNA, L.P. De invisíveis a protagonistas: populações tradicionais e unidades de conservação. São Paulo: Annablume, Fapesp, 2008.

Gabriela Narezi. Doutora em Ciências com ênfase em Ecologia Aplicada pela ESALQ - USP. Professora efetiva do Centro de Formação em Ciências Ambientais da Universidade Federal do Sul da Bahia do campus de Porto Seguro - BA. gnarezi@gmail.com 